\section{Commentary: Wherever you go, go with all your heart}

\author{
Tomasz A. Timek, MD, PhD
}

Septal myectomy has been shown to be a safe and durable procedure for relief of left ventricular outflow tract obstruction associated with hypertrophic cardiomyopathy. ${ }^{1}$ However, the surgery represents a relatively rare procedure with a median of $<1$ surgery per year per center in the Society of Thoracic Surgeons database. ${ }^{2}$ Referral to high volume-centers fosters standardization of treatment pathways and improved patients outcomes, ${ }^{3}$ yet it is possible that referral bias may contribute to differential results. Calderon-Rojas and colleagues ${ }^{4}$ from the Mayo Clinic present a large cohort of local, regional, and nation patients referred for septal myectomy. Although local patients had greater preoperative morbidity and more often required mitral valve intervention, the authors achieved excellent surgical outcome of $0.5 \%$ perioperative mortality for all patients with no differences between groups. These results are exemplary and speak to the experience and expertise of a center that has contributed greatly to our understanding of the surgical treatment of this disease.

Although the authors firmly demonstrate that referral bias does not influence outcomes at their center, a referral bias was indeed present because the national patients presented a younger and less morbid cohort that less frequently needed mitral intervention. In experienced hands, the outcomes are unaffected regardless of preoperative morbidity, yet this may not be generalizable across the country. Based on a recently published 3-year snapshot of surgical myectomies in the United States, only 16 out of 330 centers offering surgery for hypertrophic cardiomyopathy performed

\footnotetext{
From the Division of Cardiothoracic Surgery, Spectrum Health, and Michigan State University College of Human Medicine, Grand Rapids, Mich.

Disclosures: The author reported no conflicts of interest.

The Journal policy requires editors and reviewers to disclose conflicts of interest and to decline handling or reviewing manuscripts for which they may have a conflict of interest. The editors and reviewers of this article have no conflicts of interest.

Received for publication Sept 24, 2020; revisions received Sept 24, 2020; accepted for publication Sept 25, 2020; available ahead of print Oct 3, 2020.

Address for reprints: Tomasz A. Timek, MD, PhD, Division of Cardiothoracic Surgery, Spectrum Health, Michigan State University College of Human Medicine, 100 Michigan Ave, NE, Grand Rapids, MI 45903 (E-mail: tomasz.timek@ spectrumhealth.org).

J Thorac Cardiovasc Surg 2022;164:892-3

$0022-5223 / \$ 36.00$

Copyright (c) 2020 by The American Association for Thoracic Surgery

https://doi.org/10.1016/j.jtcvs.2020.09.111
}

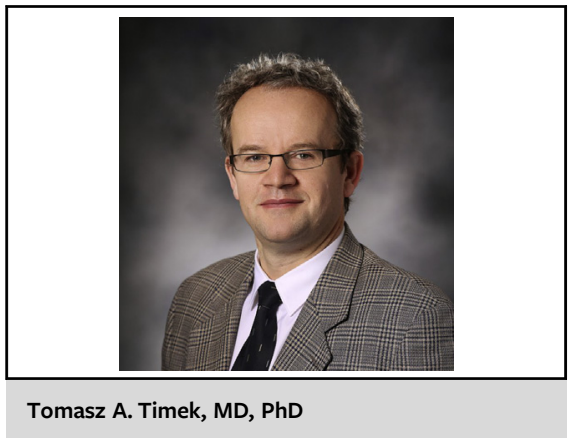

CENTRAL MESSAGE

Patients undergoing surgery for

septal myectomy at a high-

volume center have equivalent

outcomes regardless of referral

geography.

more than 7 myectomies per year. More than a half of the national of cases were performed at these high-volume centers that represented the top 5\% of centers for patient volume with an outsized influence of the Mayo Clinic and the Cleveland Clinic. The remaining centers performed $<1$ myectomy per year, suggesting that the leastexperienced surgeons are operating on the highest-risk (ie, local) patients. In analyzing surgical outcomes of septal myectomy based on hospital discharge data between 2003 and 2011, Kim and colleagues ${ }^{5}$ found in-hospital mortality of $15.5 \%, 9.6 \%$, and $3.8 \%$ for first, second, and third terciles for hospital volume, respectively. Fortunately the outcomes gap is closing, with recent data from the Society of Thoracic Surgeons database revealing a morality of $1.1 \%$ and $3.0 \%$ for low- and high-volume centers, respectively. This is in no small part due to the evangelical efforts of the Mayo group, which has standardized and simplified the procedure, disseminated their results, and generously shared their experience to the benefit of the surgical community and-above all—patients. These data demonstrate that the procedure is becoming generally safer, but further work remains. What is missing from the current report is the socioeconomic status of the different patient populations or distant outcomes. It is feasible that long-term outcomes may differ when stratified by socioeconomic status because national patients have the means to travel to a referral center and may therefore enjoy better access and superior aftercare. The authors do provide convincing data that surgical experience and high clinical volume bode 
well for all patients in need of septal myectomy regardless of ZIP code.

\section{References}

1. Ommen SR, Maron BJ, Olivotto I, Maron MS, Cecchi F, Betocchi S, et al. Longterm effects of surgical septal myectomy on survival in patients with obstructive hypertrophic cardiomyopathy. J Am Coll Cardiol. 2005;46:470-6.

2. Wei LM, Thibault DP, Rankin JS, Alkhouli M, Roberts HG, Vemulapalli S, et al. Contemporary surgical management of hypertrophic cardiomyopathy in the United States. Ann Thorac Surg. 2019;107:460-6.
3. Polanco AR, D'Angelo A, Shea N, Yu SN, Chiang YP, Shimada Y, et al. Impact of septal myectomy volume on mitral-valve replacement rate in hypertrophic cardiomyopathy patients. Cardiology. 2020;145:161-7.

4. Calderon-Rojas R, Nguyen A, Nishimura RA, Geske JB, Ommen SR, King KS et al. Is there referral bias in outcomes of septal myectomy for hypertrophic cardiomyopathy? J Thorac Cardiovasc Surg. 2022;164:881-91.

5. Kim LK, Swaminathan RV, Looser P, Minutello RM, Wong SC, Bergman G, et al Hospital volume outcomes after septal myectomy and alcohol septal ablation for treatment of obstructive hypertrophic cardiomyopathy: US nationwide inpatient database, 2003-2011. JAMA Cardiol. 2016;1:324-32.
See Article page 881.

\section{Commentary: Surgery of hypertrophic cardiomyopathy: Focus really does matter}

\author{
Jason J. Han, MD, Mark R. Helmers, MD, and \\ Pavan Atluri, MD
}

Transaortic septal myectomy is indicated for patients with obstructive hypertrophic cardiomyopathy (HCM) that is refractory to conservative treatment options. High-volume centers have reported excellent long-term outcomes, with operative mortality of less than $1 \% .{ }^{1,2}$ However, as with most specialized procedures, significant variance in outcomes has been observed, with estimated mortality as high as 5\% in national studies. ${ }^{3}$ In this issue of the Journal, Calderon-Rojas and colleagues ${ }^{4}$ explore the potential source of this variance at their tertiary institution: referral bias.

Bias is a systematic error that can falsely estimate an effect. Referral bias denotes a difference among patients who are referred to specialized centers from those in the general, local population. The authors share their

\footnotetext{
From the Division of Cardiovascular Surgery, Department of Surgery, University of Pennsylvania, Philadelphia, Pa.

Disclosures: The authors reported no conflicts of interest.

The Journal policy requires editors and reviewers to disclose conflicts of interest and to decline handling or reviewing manuscripts for which they may have a conflict of interest. The editors and reviewers of this article have no conflicts of interest.

Received for publication Sept 14, 2020; revisions received Sept 14, 2020; accepted for publication Sept 15, 2020; available ahead of print Sept 18, 2020.

Address for reprints: Pavan Atluri, MD, Division of Cardiovascular Surgery, Department of Surgery, Hospital of the University of Pennsylvania, 3400 Spruce St, 6 Silverstein Pavilion, Philadelphia, PA (E-mail: Pavan.Atluri@uphs.upenn.edu).

J Thorac Cardiovasc Surg 2022;164:893-4

$0022-5223 / \$ 36.00$

Copyright (c) 2020 by The American Association for Thoracic Surgery

https://doi.org/10.1016/j.jtcvs.2020.09.065
}

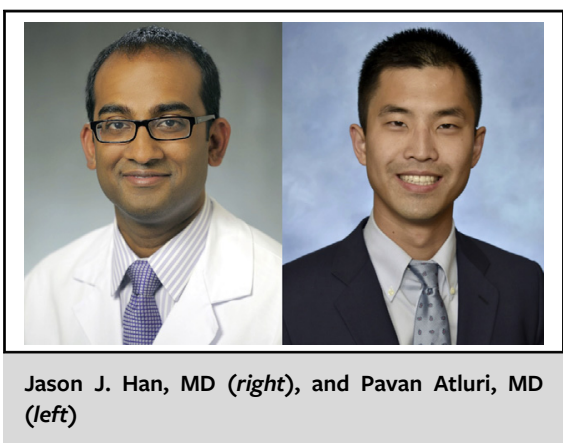

CENTRAL MESSAGE

While differences in comorbid-

ities may exist between patients

who travel short and long dis-

tances for septal myectomy,

outcomes remain superb at

centers of excellence.

extensive institutional experience conducting transaortic septal myectomy with an overall cohort greater than 2000 patients, who were divided into 3 groups based on their residence: local (Minnesota), regional (5 surrounding states), or national (remaining states). As expected, referral bias was found, as these groups had several statistically significant, albeit subtle, differences in characteristics. Local patients carried a greater prevalence of comorbidities such as diabetes, atrial fibrillation, and coronary artery disease. Similarly, the rates of concomitant mitral valve surgery and coronary artery bypass grafting performed for concomitant native cardiac diseases were about $50 \%$ greater among local and regional patients than among national patients. In contrast, nationally referred patients were generally healthier and more likely to have undergone a failed septal ablation. 